\title{
Assessment of Project Website Sustainability: Case of the Arctic EIA Project
}

\author{
Sonja H. Bickford and Angela Hollman \\ University of Nebraska Kearney, NE, USA \\ bickfordsh@unk.edu; hollmanak@unk.edu
}

\author{
Marina Nenasheva \\ Northern Arctic Federal University, Arkhangelsk, Russia
}

\author{
m.nenasheva@narfu.ru
}

\author{
Pamela Lesser and Timo Koivurova \\ University of Lapland Arctic Centre, Rovaniemi, Finland \\ pamela.lesser@ulapland.fi; timo.koivurova@ulapland.fi
}

\begin{abstract}
In many cases, temporary websites may be simple, accessible solutions for knowledge management and dissemination of information. However, such sites may become outdated as the funding ends, but yet in many cases, still publicly available through the Internet. The issue of website sustainability is a relevant topic for all organizations that have websites. Website lifecycle, knowledge management, and website sustainability issues are discussed through a theoreticalbased literature review. These issues are then summarized and used as lessons learned for the case study approach of this paper. The aim is to identify a solution to address a website's life and longevity, post project. A practical case study assessment of the issue of project website sustainability is needed to address the website's longevity - post project - as creation is often made through temporary endeavors. Recommendations for future project websites are made as the outcomes and results of this study and are expressed in the form of suggested practices for project website sustainability in future projects.
\end{abstract}

Keywords: websites, lifecycle, knowledge management, sustainability, case study

\section{Introduction}

Material published as part of this publication, either on-line or in print, is copyrighted by the Informing Science Institute. Permission to make digital or paper copy of part or all of these works for personal or classroom use is granted without fee provided that the copies are not made or distributed for profit or commercial advantage AND that copies 1) bear this notice in full and 2) give the full citation on the first page. It is permissible to abstract these works so long as credit is given. To copy in all other cases or to republish or to post on a server or to redistribute to lists requires specific permission and payment of a fee. Contact Publisher@InformingScience.org to request redistribution permission.
A practical case study assessment of the issue regarding a projects' website and its sustainability is needed to address the issue of a website's life, post project. Websites are often created through temporary endeavors, such as grant funded projects, and may become outdated once the project and its funding have ended. However, the website is often left available and accessible to the public. Often a project website's life - past the pro- 
ject's lifecycle - has been left unplanned and thus has resulted in outdated and dead links. Website lifecycle, knowledge management, and website sustainability issues are discussed and covered through a theoretical based literature review which are then summarized and used as lessons learned for the case study approach of this paper. Recommendations for future projects are made in regards to dissemination of results via a website as the outcomes and results of this study are expressed in the form of suggested practices for project website sustainability in future projects.

Information structured as web content is extremely important for an organization that needs to distribute knowledge and share information with a wider audience. Publishing web content is becoming a complex process that requires an adequate information system. This information system has to meet not only the changing Internet-related technologies, but also the creation and maintenance needs of both website authors and editors. Implementing a publishing and collaboration system where content is easily updated and system specifications are met becomes a tradeoff between these requirements (Pastore, 2006). Besides the collaboration between the authors and editors, the issue of sustainability — website's lifecycle above and beyond the project - is a relevant and timely issue because the amount of grant project work is ever increasing, especially in the field of academia.

During the past few decades, research has been conducted in project website quality, lifecycle, and statistics (Auer, Lehmann, Ngomo, \& Zaveri, 2013; Griffiths \& Christensen, 2005; Olsina, Godoy, Lafuente, G., Rossi, 1999). In addition, as stated by Gellersen, Wicke, and Gaedke (1997), the maintenance of web applications is a difficult and error-prone task because many design decisions are not directly accessible at run time, but rather embedded in file-based resources. In conducting research via search engines, it has become apparent that the dead links will stay active, and users will get an invalid, no content, or error page. Many web pages contain hyperlinks to other related pages, downloads, source documents, and other web resources. Website administrators can choose to change or update their web content. However, by neglecting to change and update sites, outdated information will be cached creating a black hole of information that will waste the users' time and energy, and seriously impact the user experience. This is a global issue that can be addressed through planning for knowledge management systems (KMS) and website lifecycle, especially in the case where a website is created for a short-term project or endeavor.

To give an example, in the case of a two-year grant funded project in Finland, the website developed by the research project team was aimed at addressing the issue of the environmental impact assessments (EIA) in the Arctic. The EIA is a legal process addressing the environmental impacts of a large scale development project during its planning-phase. The EIA process is used worldwide and is written into legislation, which describes the process and the overseeing authorities. In the United States, the National Environmental Policy Act (NEPA) describes the process and charges the Environmental Protection Agency (EPA) as the overseeing authority in cases such as the Clean Air Act. For the EU countries, the EIA Directive is then transposed into national legislation and then implemented and overseen regionally by regional centers, such as the center for economic development, transport, and the environment (ELY-Centre) in Finland. This particular EIA project, discussed in more detail later as the main case study, was developed initially through a research center in Finland because of the identified and growing interest into developing large scale projects in Northwestern Russia, and the EIA process in this particular area of Northwestern Russia was noted to be so complex that it was creating a market entry barrier for business developers into these specific Northwestern regions of Russia. It should be noted that, at this time, there was a large, growing interest in the region as this project happened prior to the current political situation. The stakeholders of this project expect and hope that the situation will return to a more positive one at some point in the near future. The website developed during this project was a solution for the market entry barrier problem as the site created an open, free, easily accessible 
location to find key information. Key EIA information was collected onsite from six different locations in Northwestern Russia, and then the website became the repository for this EIA process information, which included the location and contact information for decision makers within the legal process (Bickford, Nenasheva, Kankaanpaa, Koivurova, \& Hlavnicka, 2015). This information was current for the life of the project, which extended from 2013-2015. Before this time period, the information collected and displayed on this website was not readily accessible to corporations that wanted to enter the Northwestern Russian market. The open-access website created during the project was well received by the project's stakeholders. Stakeholders of the project included representatives from both public and private sectors in Finland. Stakeholders stated in the project's closing seminar that the created website fully addressed the market entry barrier that the country's EIA process had created. The site currently serves as an excellent example of a simple KMS serving out previously hidden knowledge and improving collaboration between corporations and the country's legal processes. The website also models information dissemination for other regions or countries where a process or regulation, such as the EIA, creates a market entry barrier.

Websites, as shown in the above-mentioned project, are an excellent tool that can minimize or eliminate such barriers. Dealing with complicated organizational situations, such as a research based institution which continuously collects and disseminates research results, requires a process for managing the organizational knowledge flow so as to achieve its organizational goals. Since a KMS is defined as an information system which supports different phases of the knowledge management (KM) process (Alavi \& Leidner, 2001), such a system is an excellent solution for a research institution, as noted above. As found by Dehghani and Ramsin (2015), when developing comprehensive processes for KMS, the analysis and maintenance phases of most KMS are poorly covered by most of the evaluated methodologies. This leads us to believe that there is a need for addressing issues of KMS sustainability, which will lead to better sustainability of project and organizational information.

As stated by Narin, Hamilton, and Olivastro (1997), scientific research - research that is performed in academic and governmental research institutions and supported by governmental charitable agencies - is the driving force behind high technology and economic growth. During the past decade, rapid growth of academic research has been seen. Contributing to this rapid growth are federal initiatives, as well as technological advances that facilitate communication and opportunities for division of labor, risk sharing, and increased research credibility (Clark, 2010; Vincent-Lancrin, 2006). Two pieces of evidence of the growth of academic research lie in the increased number of higher education researchers and the increased output of scientific articles (Vincent-Lancrin, 2006). The technological advances and increased research output has driven the need for the dissemination of results to a larger stakeholder group. Thus, it makes sense that many research projects create low-cost, easily accessible KMS through websites as part of their projects and project plans. However, many do not include or plan for the project website sustainability post-project. This has created the following question: What should a project research investigator or team do in terms of planning for their project website's life beyond the project lifecycle itself? The following discussion will focus on project implementations, which create websites to serve as simple KMS. The discussion will also focus on sustainability issues with website creation and sustainability planning. Following the theoretical literature review a case study and recommendations for future project website planning will be presented through the results section of this study. 


\section{Project Website Sustainability Planning}

\section{Literature Review}

Thousands of websites with broken links and outdated information exist (Bomberger, 2016). The reason that such broken websites exist is that the Internet is open to anyone and sites are created by all kinds of people and entities. For example, small nonprofits contributing to broken sites do not prioritize updating web content or social media due to thinly stretched resources (Greenberg \& MacAulay, 2009; Mansfield 2012; McMahon, Seaman, \& Buckingham, 2011). Universities often use short-term grant funds to document and evaluate various projects (Vogel, Seifer, \& Gelmon, 2010) and often do not have resources to maintain projects, and the associated websites, in the long term. Thus, examples of dead or outdated websites can be found throughout the web in most fields and countries. Knowledge and information are valuable resources that must be achieved, disseminated, and sustained.

Knowledge is more relevant to sustained business than capital, labor, or land (Geisler \& Wickramasinghe, 2015), and stakeholder involvement in most research and projects is an important factor. In many cases, stakeholder involvement and participation is seen as a key factor to ensure that investigations are completed for certain target groups and types of organizations and meet their needs and demands (Pawlowski \& Bick, 2015). In recent years, the usage of KMS, often in combination with information and communication technology (ICT), has contributed to many stories of organizational success (Wilson, 2002). Organizations often use KM to strategize their next maneuver within the marketplace to create sales growth or to gain deeper understanding about their market share (Salojarvi, Furu, \& Sveiby, 2005). Within the realm of KM research, many projects have been funded to help corporations implement a new initiative or process. The purpose of such funded initiatives, in one instance, was to provide a strategy for corporations, particularly in a rural, non-developed area, to overcome barriers into a new marketplace (Bickford et. al., 2015). A project of this manner provides a doorway for corporations to enter into a rural area, where certain processes and procedures may otherwise hinder much needed progress and growth (Nenasheva, 2014). The main toolkit used within this particular KM research project was a web application, which provided the corporations with the needed information to overcome a large market entry barrier serving as a simple KMS (Bickford et al., 2015).

Looking deeper at project funding for such initiatives, the main problem, as discussed in this article, is incorporating sustainability of the implementation element within the current process, which currently uses web applications as a major component. When defining sustainability, this study concentrates on the applied implementation portion of a short-term funded project revolving around the usage of a website application, which provides ongoing support for the KM strategy or initiative. Sustainability is a term that has a variety of meanings, and in this case we define sustainability as longevity of the website's lifecycle past the project's lifecycle itself. This study is also under the assumption that the website application created, not only supports the initial implementation of the KM initiative, but also helps sustain the KM initiative providing continual benefits to that of the stakeholders (Drucker, 1990; Hall \& Hord, 2001). This differs from many short-term projects which only delve in planning and piloting aspects.

Since the public health sector has a pool of research involving short-term funding for project initiatives that are then implemented and presented to public stakeholders, literature has been drawn from this genre to provide a theoretical framework. First of all, main reasons from the public health community initiatives literature should be considered as it addresses why sustainability within the short-term funding process presents such a large problem. Pluye, Potvin, and Denis (2004) emphasize that programs with short-term funding need to be implemented long-term to allow for time to recognize the impacts being made. If programs are not sustained, the parties 
involved (including corporations and communities) will not only lose interest, but also the time and money that was initially invested upfront. This leads corporations and communities to become dissatisfied and hesitant to enter into any more future projects (Goodman, Steckler, Hoover, \& Schwartz, 1993; Shediac-Rizkallah \& Bone, 1998). Thus, a total loss of not only sustainability but the initiative of the entire project. To try and provide a model of sustainability, Johnson, Hays, Center, and Daley (2004) provided a planning model, which emphasizes not only the importance of project longevity, but also the importance of stakeholder relationships within the sustainable project. Planning for sustainability of implementation initiatives, especially those involving web applications, is a challenge and one that has not yet been addressed in many KM projects. Also, Touré, Michel, and Marty (2016) stated that integrating and including material and information in implemented information systems that aims to increase and influence awareness and create more positive beliefs about the systems will, in turn, help create solutions for models, processes, and sustainable use. Many short-term grant funding sources require newly implemented initiatives or methods to present evidence on the effectiveness, which proves difficult due to to the short timeline and often limited resources. Providing a website application as the implementation methodology gives the plan for implementation not only a clear focus, but provides a wide range of accessibility to all stakeholders and technological platforms and information can be widely disseminated as often directed by stakeholders or project sponsors. Thus, the website application becomes an immediate go-to platform when choosing an implementation methodology.

However, the problem, addressed in this paper, is how such a website application is sustained after the initial funding process is over. Grant funding and other funding mechanisms typically support new processes and initial implementations. After this funding is spent, the sustainability of the implementation becomes, essentially, impossible to fund. Applying for additional grant funding to sustain an already implemented process is very hard to find, and even then, will also expire after a short-term period of, on average, 1 to 3 years. As described through the case study and stated by Dehghani \& Ramsin (2015) there is a need for solutions for sustainable KMS processes and methodology that addresses the unique needs of short term projects with limited funding, but that have a long-term continued impact and serve the needs of a larger stakeholder and user group. In looking at the case study and best practice recommendations, a potential solution to the problem of supporting ongoing websites through short-term funding projects might be found.

\section{Case Study - Arctic EIA Project Website}

Too often websites become obsolete and outdated due to a lack of planning for sustaining and updating the information in the future. During the University of Lapland Arctic Centre's two-year (2013-2015) Arctic EIA project, the topic was widely discussed throughout the project's life. Both the project team members, consisting of an international group of researchers from Finland and the United States, as well as the project's stakeholder group, consisting of representatives from large industries, key public decision makers in the field of environmental impact assessments, and representatives from non-governmental organization, all agreed and recommended that one of the key deliverables from the project work, the Information Service (IS)-Russia website, needed to have a sustainability plan for the long term. This key deliverable of sustainability planning would help alleviate the website from dying on the vine after the project was over and the budget had run out. Most people at some point have landed on these dead links or outdated webpages; the information is great, but would be more valuable if updated. The main question and goal of this study is to identify a solution to address a website's life and longevity, post project. More specifically, how can our project's website, IS-Russia, be different from so many others prior to this one? Key points requested from the institution and the project team were that the website remain in the Arctic Centre's domain and ownership as the goal is to expand upon this initial study. This study used a focus group consisting of the project team, the institution providing funding, and the project's stakeholder group to answer this question. Other questions that 
needed to be answered and addressed here are the following: Who is the audience and users of this site? What do they need? How often will the site be used? These questions determine the viability of the site's longevity and define the need to keep such sites active, post project.

Through planning and end user feedback and recommendations, the project team identified key needs for the website. The site contains time-sensitive data, such as key contact information that is not widely available. Also, new regulations and laws impacting the EIA process and system will need to be monitored and added to the site as those become relevant in the six regions the original project study covered (Bickford et. al., 2015).

Recommendations and wishes from both the project team and the stakeholders for the future of the current IS-Russia website were collected and analyzed. Information and feedback was collected through direct feedback at project specific seminars and meetings, as well as through the feedback webpage which was posted on the website. For example, stakeholders requested that the well-received initial IS-Russia website be used as a model for the creation of similar websites for the other seven (7) Arctic countries as the information collected does help lower the market entry barrier. The market entry barrier was lowered by providing key information on the website about the EIA projects and decision makers for the regions. The stakeholders also requested that new pages and updates should be continually added to keep the market entry barrier low.

Based on the analysis of the requests, suggestions, and feedback, five different options for the website's sustainability plan are identified. These five different options were all created around the key theme of providing the site and its end users a longer-lived, current, website and service. Each option is identified and described along with the pros, cons, and identified risks, which helps answer the initial question of how to plan for sustainability of simple KMS through websites during a temporarily funded project.

\section{Option 1: Charge a Fee for Site Content or to Advertise on the Site}

The first option identified to address the issue of website sustainability into the future was to charge a fee for site content or to advertise on the site. The reasoning behind this solution was the fact that this would allow the institution, or the owner of the website, to generate funds to hire the required staff to maintain the website as needed. Within this option, as the website was created as a free, open access site, the most likely solution that would still fulfill the mission of the site, but also address the needs of the host institution, would be to simply charge a few for advertising on the site. Initially this could be done on an annual basis to assure that all contact information and regulations are up to date. The information collected for the IS-Russia website's content was done in person through six fact-finding trips in the regions of interest in Northwestern Russia. These trips established key business relationships while collecting the needed information. In Russia, fact-finding must be done through a very formal network as the country ranks very high on Hofstede's cultural dimensions in regards to power distance and uncertainty avoidance (Bickford et. al., 2015). The pros of this option are that the website ownership remains with the Arctic Centre, the initial creator of the website, and that the funds generated would also go to offset overhead costs for the institution. One major con of this option is that hiring the specialized personnel required to obtain the information needed of the website could be very challenging. This challenge arises when someone attempts to assess the laws and regulations and locate the key individuals and their contact information for those involved the EIA process in Russia. In addition, this option would go against the original project plan where the aim of the project was to create a free, open-access website. The risks associated with this option are that the amount of funds generated through advertising would not cover the site fee or the salary for the specialized personnel required for the site's annual maintenance. 


\section{Option 2: Research-for-contract Model}

This option builds upon a case study business model tested during the Arctic EIA project (20132015) as well as a framework for assessing and managing the university technology business incubator (UTBI) as a tool for new venture creation (Mian, 1997).

During the project a key member of the stakeholder group requested a special case study report, about how their specific business would be impacted by the EIA legislation if they chose to grow their business in the region in question. This case study is posted as an example on the Arctic EIA website (IS-Russia, 2015). Within this research-for-contract model, this specialized case study research would be offered as a paid service and the funds generated would provide the required budget to hire on personnel to update and maintain the website into the future. The stakeholders and other interested parties would request specialized services and analysis of the research team and Arctic Centre in regards to information for decision making for their respective business strategies. The case studies and applied business research for the clients would be conducted on a contract basis, and thus funds would be generated for the researchers conducting the specialized data collection and analysis. These fees could also serve to offset overhead for the institution, which is taking on the initial website's maintenance. The website could then continue to serve as a portal for the business requests. Following project management theory and as suggested in the original project's business model and in the case of most temporary projects, the deliverables and future plans should be planned prior and during the current projects execution (Haugan, 2010). The research-for-contract model operates as a perfect example of a long-term roadmap deliverable by providing continued services for companies that need additional research in regards to the process or impacts of EIAs in the Arctic. The sustainability of the research-for-contract model is already vetted through the need for the established case study and the impact that the EIA has on a company's business decisions and strategies. The pros of this option are that the website's ownership would remain with the Arctic Centre, where a connection with the stakeholders has already been established. The site and the established professional business network would provide the opportunities for continued work and projects for the Arctic Centre as well as a potential for collaborative projects and business opportunities in Finland and abroad. This option could also provide future project work for the original project team of the Arctic EIA project, thus supporting the Arctic Centre in multiple ways through research as well as potential future contract work. Some of the cons of this particular option include the hiring of the specialized personnel to assess the laws and regulations and locate the contact information for the people in the EIA process in Russia. Since this is such a specialized field, the personnel may be difficult to find. Also, the newly established IS-Russia website or even the new research-for-contract model proposed may not generate enough funds.

\section{Option 3: Crowdfunding: Secure a Group of Business Sponsors}

The third option identified to address the project website's sustainability issue is to identify and secure a group of organizations willing to sponsor the site. This sponsorship would entail updating and maintaining the website for a certain period of time. By identifying a group of businesses willing to sponsor the site, not only would the required funding would be provided, but this would also prove that the business supports and values the website and information provided. Through this sponsored business group approach, the businesses would provide foundational funding for the purpose of not only maintaining the website but also strategizing on ways for the website to pay its own way. This option is similar to crowdfunding and could provide the needed financial support required for the maintenance of the site after the life of the project. Crowdfunding is defined as a method where an entrepreneur raises external financing from a large audience (the "crowd"), in which each individual provides a very small amount (Belleflamme, Lambert, \& Schwienbacher, 2014). In this option, the crowdfunding idea is flipped. The businesses become 
the crowd, in which the funding is sourced, and the website becomes the entrepreneurial endeavor that needs funding. The pros of this crowdfunding option are that the website ownership remains with the Arctic Centre. However, as a part of the business sponsorship, the businesses involved would get name recognition and more marketing visibility on the website. Those providing support would also be able to advise the Artic Centre and have an inside track to research and development being done on the website project. Cons of the option include the hiring of the specialized personnel to assess the laws and regulations and locate the contact information for the people in the EIA process in Russia, which can be challenging. In addition, the fine line of input and buy-in from site sponsors must be managed to where sponsors must feel that their input is valid and used, but yet the website owners remain in control of the site and its content. This can also be considered a risk of this option. In addition, to the risk that not enough funds will be raised by sponsor organization/business and/or organizations/businesses.

\section{Option 4: A New Project Proposal}

In the fourth option, the model is to create a new project proposal using the initial EIA website as a pilot endeavor. The new project proposal would seek to create additions to the initial site by asking for an extension on temporary funding from the Arctic. This proposal could have either an academic research focus or an applied research focus directed at a stakeholder or group of stakeholders that have a need and use for such a website tool. There are many more businesses interested in pursuing projects that will require an EIA in other Arctic countries. The reasoning for this option is that the Arctic Centre is a world-renowned research center focused on being the information hub. Thus, projects that involve the Arctic - particularly within the realm of innovative research, networking, and entrepreneurship - are projects that are of keen interest for the Centre. Since this builds on expertise through an already established EIA Arctic project with a known stakeholder group, the aim of the project proposal would be to expand the website gathering a more comprehensive look at EIA information, using the IS-Russia as a model. This makes sense for many of the Arctic countries and fits well into the scope and mission of the Arctic Centre itself. This option also fulfills the Arctic EIA project sponsor's, the Finnish Funding Agency for Technology and Innovation (Tekes), aim of funding projects that answer a direct need from businesses and offers a tangible deliverable for the end-users or stakeholders of projects (Tekes, 2015). The identified pros of this option for the website's sustainability are that the website ownership remains with the Arctic Centre, which has been established as highly necessary. The option also opens the door for new research opportunities by creating a clear methodology of using websites to provide EIA information and establishing a clear system to do so. This option also maintains and grows networking opportunities for the project team, the Arctic Centre and its vast international network of stakeholders that has been established in this strategic project. The cons include the fact that the proposed option could be a temporary solution because there are only a finite number of Arctic countries that need an EIA website to overcome a market entry barrier. After this finite number is exhausted, the funding will also stop. The next project, if funded, will have the same issue of planning for the now improved and grown website after the project and its funding is over. Risks for this proposed option include the unknown source and amount of funding for a new project as these are not guaranteed and may take time to secure.

\section{Option 5: Addition to Job Requirements}

The fifth identified option is that the website's maintenance work would be added to a current or future job description. For example, the departments that most often have interns would add the website's updating and maintenance to the intern's workload. An intern is a rotating position, most often for 6-12 months, but the collecting and updating the current website's content could be simplified and assigned as the intern's task. Other variations within option 5 would be to include the duties and tasks into the Centre's website manager or coordinators' jobs, as they are the ones 
who routinely check the Arctic Centre's and University's pages. The reasoning behind this option is that the Arctic Centre already employs a steady stream of interns. More specifically, the department of The Northern Institute for Environmental and Minority Law (NIEM) within the Artic Centre, where the initial Arctic EIA project work was conducted, could include the website's maintenance into every intern's required tasks for the duration of their employment at the institute since the field is similar and familiar to those students. The pros of this option are again that the website's ownership remains with the Arctic Centre and the intern would gain valuable in business research. A highly motivated intern may even find new opportunities and projects for the department, or even the Arctic Centre. This would be a way to provide an intern with real world, hands-on experience in the legal, business, and technology fields. The noted cons of this option are that the interns may not have the capabilities or expertise required to collect the information required for the site and the cost of an intern's time spend on the website will need to be covered (one month) by the project, department, or institution. The other hidden cost is the needed travel that may be incurred to collect the contact information through Russia's formal network. The risks of this option are that there may be a period when there aren't any interns in the NIEM department and the website again goes un-maintained. Another possibility is that the training needed for updating and maintaining the site is misplaced or not passed on correctly.

\section{Recommendations}

The issue of website sustainability is a relevant topic for all organizations that have websites. However, the time-sensitive, project-based website needs to be up-to-date and relevant during the project period. The issue of website life post project needs to be addressed at the planning and execution strategies of the project itself so that there is reasonable amount of time to match the solution for the project and organization. As stated by Touré et al. (2016), awareness and acceptance of the issue is the start of creating a solution for a revised process and method for sustainable KMS. In the Arctic EIA project case, the issue was addressed by developing five options that addressed the key issues identified by the project's researchers and stakeholders. The goal was to have the site hosted by the project organization, the Arctic Centre, and generate enough funds to cover the work load that is needed for the website on an annual basis. These solutions were developed and then presented to the project's team, steering committee, and large stakeholder group at the final steering as a part of the final project seminar held in December 2014. At this time, option four was ideal in combination with option five, as option four was in line with the mission of the host institution itself. However, with all things considered and due to time constraints the most feasible option at the time was option five with the efforts put into option four in the near future. Thus the solution was to add the tasks to the current website manager's routine maintenance. With this solution, the website would remain with the Arctic Centre, which was a crucial factor in creating the options, and required no additional funds or support at this time. However, the known risks of this option are the fact that the key contact data may not be updated in a timely manner, as this requires extensive work in the field in Russia. The original project researcher who created the website has volunteered time to update the contact information during the first year post project in order to gauge the frequency and time required for a continual process and develop a methodology that can then be passed on as instructions for the site's upkeep into the future. It is recommended that projects that create websites acknowledge the issue of the project and website lifecycle and create a plan to address the sustainability of information through a KMS and process that matches the mission and goals of the host organization. 


\section{Conclusion}

Websites become obsolete and outdated, especially in the project world where websites are often created through temporary endeavors, such as grant projects. Knowledge management and dissemination of results to a wider audience and stakeholder group is often done digitally through websites. These websites, during the life of the project, are easy to maintain, organize, and collect feedback from the intended target audience of the project. However, a lack of planning for the project's future, specifically post-project, during the project's initiation period may result in the information on the project website, such as results, to show up as dead links post project. Another consequence created with the deficiency in planning is the absence of site responsibility or ownership. In addition, these websites are often left available and accessible to the public post project and have relevant information, but, in majority of cases, it has become out of date. A practical case study assessment of the issue of project website sustainability is needed to identify key issues relevant to each unique project endeavor and its goals. If a project website's life, especially past the project's lifecycle, has been left unplanned it is more likely that the site will become outdated and contain dead links sooner than those that have addressed the issue in one way or another. The lessons learned from the case study approach of this paper provide the base for the recommendations for future projects. It has been found that awareness of issues is a crucial starting point in developing a sustainable KMS and planning for a website's lifecycle. Five options for website sustainability are suggested as examples of how issues of project website sustainability in future projects can be addressed. Successful implementation of the current solution will be addressed annually via testing the websites information for accuracy. Based on the case study, it is recommended that each project and project team conduct additional research into their particular end-user and funder/sponsor needs, goals, and demands for their website and through this process address issues of the sites purpose and usefulness pre-, during, and post- project so that the option that has the best fit for that particular project can be selected.

\section{References}

Alavi, M., \& Leidner, D. E. (2001). Review: Knowledge management and knowledge management systems: Conceptual foundations and research issues. MIS Quarterly, 25(1), 107-136.

Auer, S., Lehmann, J., Ngomo, A. C. N., \& Zaveri, A. (2013). Introduction to linked data and its lifecycle on the web. In Reasoning Web. Semantic technologies for intelligent data access (pp. 1-90). Springer Berlin Heidelberg.

Belleflamme, P., Lambert, T., \& Schwienbacher, A. (2014). Crowdfunding: Tapping the right crowd. Journal of Business Venturing, 29(5), 585-609.

Bickford, S., Nenasheva, M., Kankaanpaa, P., Koivurova, T., \& Hlavnicka, A. (2015). Online information system - Russia aims to ease the environmental impact assessment (EIA) market entry barrier into northwestern Russia. Communications of the IBIMA, 2015. doi:10.5171/2015.185611

Bomberger, A. (2016). The complexities of community-based websites. Metropolitan Universities. 26(2), 185-199.

Clark, B. (2010). The effects of government, academic, and industrial policy on cross-university collaboration. Science and Public Policy, 37, 314-330.

Dehghani, R., \& Ramsin, R. (2015). Methodologies for developing knowledge management systems: An evaluation framework. Journal of Knowledge Management, 19(4), 682-710.

Drucker, P. (1990). Managing the non-profit organization: Principles and practices. New York: Harper.

Gellersen, H. W., Wicke, R., \& Gaedke, M. (1997). WebComposition: An object-oriented support system for the Web engineering lifecycle. Computer Networks and ISDN Systems, 29(8), 1429-1437. 
Geisler, E., \& Wickramasinghe, N. (2015). Principles of knowledge management: Theory, practice, and cases. Routledge.

Goodman, R., Steckler, A., Hoover, S., \& Schwartz, R. (1997). Mobilizing organizations for health enhancement. In K. Glanz, F. Lewis, \& B. Rimer (Eds.), Health behavior and health education: Theory, research and practice (pp. 287-312). San Francisco: Jossey-Bass.

Greenberg, J., \& MacAulay, M. (2009). NPO 2.0? Exploring the web presence of environmental nonprofit organizations in Canada. Global Media Journal, 2(1), 63-88.

Griffiths, K. M., \& Christensen, H. (2005). Website quality indicators for consumers. Journal of Medical Internet Research, 7(5).

Hall, G., \& Hord, S. (2001). Implementing change. Boston: Allyn \& Bacon.

Haugan, G. T. (2010). Project management fundamentals: Key concepts and methodology. Vienna, Virginia: Management Concepts Inc.

IS-Russia. (2015). Information Service - Russia. [Online] www.arcticcentre.org/RussianEIA

Johnson, K., Hays, C., Center, H., \& Daley, C. (2004). Building capacity and sustainable prevention innovations: A sustainability planning model. Evaluation and Program Planning, 27(2), 135-149. Doi:10.1016/j.evalprogplan.2004.01.002

Mansfield, H. (2012). Social media for social good: A how-to guide for nonprofits. New York: McGraw Hill.

McMahon, D., Seaman, S., \& Buckingham, J. (2011). Nonprofit adoption of websites and website types. Journal of Marketing Development and Competitiveness, 5(6), 43-50.

Mian, S. A. (1997). Assessing and managing the university technology business incubator: An integrative framework. Journal of Business Venturing, 12(4), 251-285.

Nenasheva, M. (2014). A company specific case study on Russian environmental impact assessment (EIA). Retrieved from http://www.arcticcentre.org/loader.aspx?id=b03b5722-0df7-4fee-b508-0bac3fa4d7fb

Narin, F., Hamilton, K. S., \& Olivastro, D. (1997). The increasing linkage between U.S. technology and public science. Research Policy, 26(1997), 317-330.

Olsina, L., Godoy, D., Lafuente, G., \& Rossi, G. (1999). Assessing the quality of academic websites: A case study. New Review of Hypermedia and Multimedia, 5(1), 81-103.

Pastore, S. (2006, August). Web content management systems: Using Plone open source software to build a website for research institute needs. In Digital Telecommunications. 2006. ICDT'06. International Conference on (pp. 24-24). IEEE.

Pawlowski, J. M., \& Bick, M. (2015). The global knowledge management framework: Towards a theory for knowledge management in globally distributed settings. Leading Issues in Knowledge Management, 2(2), 134.

Pluye, P., Potvin, L., \& Denis, J.-L. (2004). Making public health programs last: Conceptualizing sustainability. Evaluation and Program Planning, 27(2), 121-133. doi: 10.1016/j.evalprogplan.204.01.001

Salojarvi, S., Furu, P. \& Sveiby, K. (2005). Knowledge management and growth in Finnish SMEs. Journal of Knowledge Management, 9(2), 103-122.

Shediac-Rizkallah, M. \& Bone, L. (1998). Planning for the sustainability of community-based health programs: Conceptual frameworks and future directions for research, practice and policy. Health Education Research, 13, 87-108.

Tekes. (2015). The Finnish Funding Agency for Technology and Innovation [Online] https://www.tekes.fi/en/ 
Touré, C., Michel, C., \& Marty, J. C. (2016). What if we considered awareness for sustainable knowledge management? Towards a model for self-regulated knowledge management systems based on acceptance models of technologies and awareness. arXiv preprint arXiv:1601.08030.

Vincent-Lancrin, S. (2006). What is changing in academic research? Trends and future scenarios. European Journal of Education, 41(2), 169-202.

Vogel, A. L., Seifer, S. D., \& Gelmon, S. B. (2010). What influences the long-term sustainability of service-learning? Lessons from early adopters. Michigan Journal of Community Service Learning, 17(1), $59-76$.

Wilson, T. (2002). The nonsense of knowledge management. Information Research, 8(1), paper 144.

\section{Biographies}

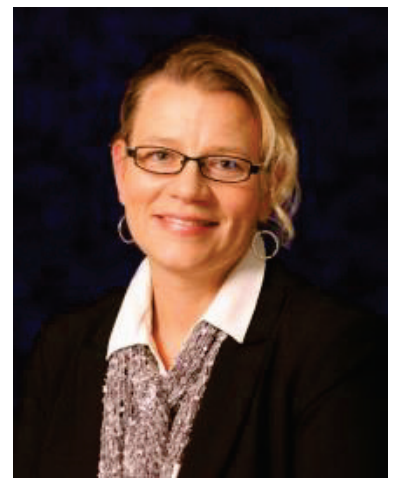

Sonja H. Bickford, DBA, MBA. Prior to her current appointment as lecturer in the industrial technology department at the University of Nebraska Kearney (UNK), Dr. Sonja H. Bickford was an Assistant Professor of Business at the University of Great Falls in Montana, as well as the Director of Study Abroad. She was also a key member of an international research project (Arctic EIA) that focused on assessing the modes of best practices of environmental impact assessments in the Arctic and the EIA market entry barrier into Northwestern Russia through the development of the Information Service - Russia.

Her research interests include rural and Arctic business practices, environmental impact assessments, international business cultures, social impact assessments, corporate responsibility, cost benefit analysis, business models, and best practices.

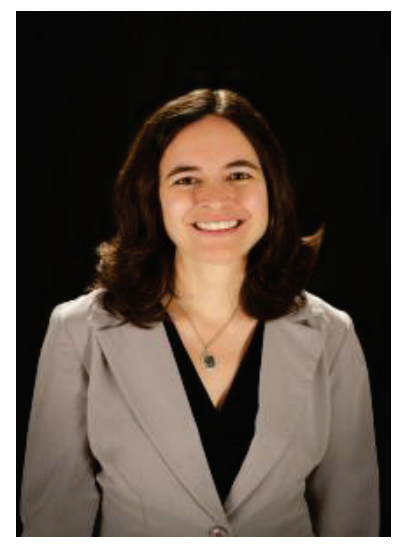

Angela K. Hollman, Ph D, is an Assistant Professor of Information Networking and Telecommunications (INT) in the Industrial Technology Department at the University of Nebraska at Kearney (UNK). She has led multiple enterprise-level projects in her previous 10-year stint in the information technology (IT) industry as a manager of the networking team. She also currently co-owns a web applications company. Due to this multi-disciplinary background, her research frequently intertwines IT, cybersecurity, entrepreneurial and business aspects examining frameworks and theories that might move the needle to closer collaboration between these groups. Dr. Hollman has been teaching at UNK for the past 5 years.

She holds a doctorate degree in Educational Administration from the University of Nebraska at Lincoln, as well as baccalaureate and master's degrees in Instructional Technology and Computer Science and Information Systems from UNK. She has also completed teaching certifications for networking and systems studies and holds several IT industry certifications. 


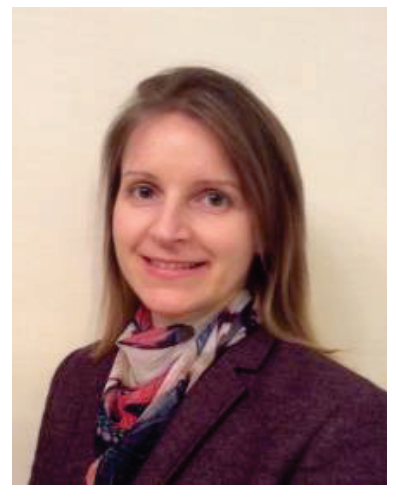

Marina Nenasheva, $\mathbf{P h} \mathbf{D}$, is a Lecturer at the Department of Sociology and Philosophy at the Northern Arctic Federal University in Arkhangelsk, Russia. She has a PhD degree in Philosophy of Science. She is also a Director of the Environmental Law Center in Arkhangelsk.

Marina's professional interests include practical aspects of Russian Environmental legislation use, national and international environmental and social impact assessment, and sustainable development in the Arctic. She has participated in the project "Testing improvement processes of Finnish environmental impact assessments and the modes of application in the arctic regions of Finland and Russia" as a Researcher on Russian Environmental Impact Assessment (EIA) and Co-creator of the Information Service on Russian EIA.

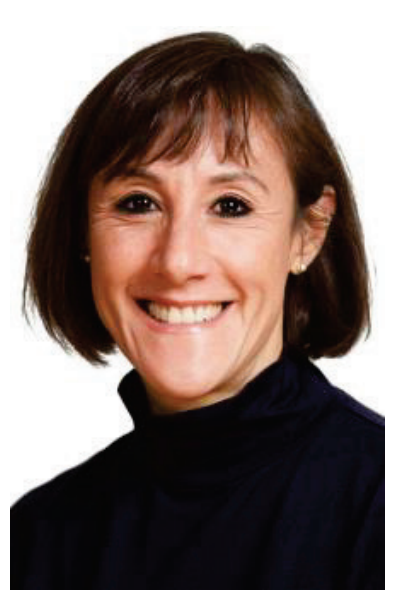

Pamela Lesser, MS, is a Researcher at the Arctic Centre, University of Lapland (Finland), where she focuses on sustainable mining practices in the north. Her current research looks at implementing the social license to operate concept in the Nordic region. Prior to her work at the Arctic Centre, Ms. Lesser was a Fellow of Ecologic Institute - U.S., a Berlin-based think-tank, with projects related to smart cities and spatial planning. Ms. Lesser has extensive experience in the public sector, working for consultancies as well as with NGOs. As the National Policy Analyst at ICLEI - Local Governments for Sustainability USA, she served as a policy advisor to the Executive Director. Pamela Lesser was educated at Georgetown University, the University of California, Los Angeles (B.A., Political Science, M.A., Urban Planning), and conducted post-graduate studies in environmental policy at the RAND Corporation and in environmental science and policy at Johns Hopkins University in Washington, DC.

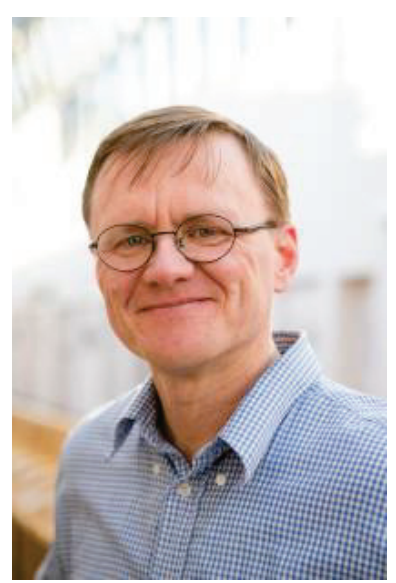

Professor Timo Koivurova, JD, is the Director of the Arctic Centre, University of Lapland. He is also a Docent of International Law at the Faculty of Law, Economics and Business Administration/University of Eastern Finland and at the Faculty of Law/University of Turku. Koivurova has written a widely read textbook on international environmental law and serves as the chair of the University of the Arctic's Arctic Law Thematic Network. He also serves on the board of the Arctic Research Consortium of the United States (ARCUS) and on the board of Iceland's President new forum; the Arctic Circle.

Professor Koivurova's expertize covers, among others, Arctic legal and governance questions, international environmental law, and indigenous rights. 